\title{
Drogas e Sistema Nervoso Periférico
}

II - Miopatias Tóxicas

Drogas e Miastenia Gravis. Drogas e Porfirias. Síndrome Neuroléptica Maligna e Hipertermia Maligna

Roger Gomes Reis*

Acary Souza Bulle Oliveira**

\section{RESUMO}

Um grande número de drogas tem implicado dano muscular ou disfunção da transmissão neuromuscular. Apresenta-se uma revisão dos aspectos clínicos e dos variados mecanismos patofisiológicos, que envolvem tanto efeitos diretos quanto indiretos.

Os autores discutem ainda três condições clínicas farmacogenéticas que dependem basicamente de drogas desencadeantes para se manifestarem: as porfirias, a síndrome neuroléptica maligna e a hipertermia maligna.

\section{UNITERMOS}

Miopatia, drogas, toxicidade.
Médico estagiário do Setor de Doenças Neuromusculares da Disciplina de Neurologia do Departamento de Neurologia e Neurocirurgia, Unifesp-EPM.

** Doutor em Neurologia e chefe do Setor de Doenças Neuromusculares da Disciplina de Neurologia do Departamento de Neurologia e Neurocirurgia, Unifesp-EPM.

\section{MIOPATIAS TÓXICAS INDUZIDAS POR DROGAS}

O tecido muscular é altamente sensível a drogas e toxinas, devido à sua intensa atividade metabólica e aos múltiplos sítios suscetíveis na geração de energia que podem ser afetados.

$\mathrm{O}$ efeito pode ser direto ou indireto, como no caso de drogas indutoras de hipocalemia, causando rabdomiólise. Fatores farmacocinéticos adversos dependentes do indivíduo ou comprometimento neuromuscular prévio são fatores predisponentes para a miotoxicidade da maioria delas.

As miopatias tóxicas são, na discussão que se segue, classificadas em:

- Miopatias necrotizantes

- Miopatias por desordem lisossômica

- Miopatias antimicrotubulares

- Miopatias inflamatórias

- Miopatias por hipocalemia

- Miopatias por desordem mitocondrial

\section{Miopatias necrotizantes}

Os inibidores da hidroximetilglutaril coenzima A (HMG-CoA) e os fibratos são o protótipo desse grupo. A mionecrose é também relacionada ao uso de ácido e-aminocapróico, aos retinóides sintéticos e às altas doses de vitamina E.

Clinicamente, podem cursar desde envolvimento leve, com mialgias e elevação pouco significativa da creatinocinase (CK), até quadros de mionecrose intensa com mioglobinúria e insuficiência renal aguda.

Os inibidores da HMG-CoA, em uso, incluem a lovastatina, a sinvastatina, a mevastatina, a pravastatina e a fluvastatina. Há poucos relatos de miotoxicidade com a sinvastatina, mas não há evidência farmacológica convincente a favor ou contra qualquer uma delas. $\mathrm{O}$ maior número de casos 
com a lovastatina parece dever-se ao seu uso mais disseminado ${ }^{1}$. A prevalência de elevações leves da CK e mialgias, sem fraqueza ao exame clínico, desenvolvese de forma transitória em até $5 \%$ a $10 \%$ dos pacientes, enquanto quadros francos de mionecrose e quadriparesia sejam mais raros, tendo ocorrido em apenas $0,1 \%$ dos pacientes do estudo EXCEL ${ }^{2}$. No estudo escandinavo $4 \mathrm{~S}$, dos 2.222 pacientes que receberam sinvastatina, somente 6 desenvolveram hipercreatinocinasemia ${ }^{3}$.

Essas drogas diminuem a síntese de ácido mevalônico, o qual é um precursor de vários metabólitos essenciais, como o colesterol, as ubiquinonas e o dolicol. A miotoxicidade parece depender desses desarranjos metabólicos ${ }^{1}$. O estudo histoquímico da lesão experimental em ratos mostra acometimento inicial das fibras 2B, com degeneração mitocondrial e do retículo sarcoplasmático; com a administração prolongada, todos os tipos de fibras são afetados. A histopatologia em humanos, durante a fase aguda, mostra mionecrose, infiltrado mononuclear com miofagocitose e alterações regenerativas. A microscopia eletrônica mostra acúmulo subsarcolemal de lisossomos ${ }^{4,5}$.

$\mathrm{O}$ risco de miotoxicidade aumenta com determinadas associações. A combinação com fibratos, principalmente a genfibrozila, e ácido nicotínico, que pode ser necessária em pacientes com níveis muito altos de LDL, com hipertrigliceridemia e doença ateromatosa sintomática, é o exemplo mais comum. Casos fatais com radomiólise maciça foram descritos após a associação com a ciclofosfamida. As duas drogas podem ser usadas conjuntamente, se estritamente necessário, desde que a dose do hipocolesterolemiante seja reduzida (10 a 20 $\mathrm{mg} / \mathrm{dia}$ de lovastatina e 5 a $10 \mathrm{mg} /$ dia de sinvastatina). A combinação com eritromicina, principalmente estolato, e outras drogas colestáticas (esteróides anabólicos, anticoncepcionais orais e andrógenos, clorpropamida, nitrofurantoína e fenotiazínicos) e a presença de disfunção hepatobiliar ou renal são outros fatores de risco aumentados para sua miotoxicidade.

O clofibrato 6 foi o primeiro derivado do ácido $\mathrm{p}$ clorofenoxi-isobutírico a ser utilizado como hipotrigliceridemiante. Perdeu espaço para derivados mais eficazes e menos tóxicos, como o bezafibrato, o fenfibrato, a genfibrozila e o ciprofibrato. A miotoxicidade parece ser maior com o clofibrato que com a genfibrozila, e os primeiros relatos surgiram em 1968. A mioglobinúria não representa um achado importante, predominando mialgias e elevações leves a moderadas da CK, reversíveis com a suspensão da droga. Pacientes com insuficiência renal estão sob maior risco. A combinação com lovastatina já foi citada.
Há relatos de três casos de mialgia e hipercreatinoquinasemia com o uso de ácido nicotínico ${ }^{7}$. Os pacientes não foram biopsiados, e um deles estava também em uso de clofibrato.

Mionecrose e mioglobinúria são complicações bem estabelecidas do ácido e-aminocapróico ${ }^{1}$, principalmente com o uso prolongado, pouco empregado atualmente. É um análogo da lisina e parece competir com essa na síntese de carnitina, resultando em um estado de deficiência aguda desse substrato.

O consumo de altas doses de vitamina $\mathrm{E}^{1}$ pode causar miotoxicidade por mecanismos pouco estabelecidos. Alguns pacientes desenvolvem fraqueza proximal e hipercreatinocinasemia moderada. Achados de biópsias têm demonstrado uma miopatia necrotizante que caracteristicamente exibe acúmulo paranuclear e subsarcolemal de material granular em fibras tipo I exclusivamente.

$\mathrm{O}$ etretinato, um derivado aromático da vitamina $\mathrm{A}$, pode causar mialgias e fraqueza proximal. Esparsos relatos de biópsias mostram mionecrose leve. Com a isotretinoína, as mialgias leves e transitórias podem ocorrer no início do tratamento e, geralmente, desaparecem com o uso continuado ${ }^{8}$.

Uma relação das drogas que, por mecanismos diretos ou indiretos, causam rabdomiólise é fornecida na tabela 1 .

\section{Miopatias por desordem lisossômica}

As drogas desse grupo são representadas pelos compostos catiônicos de propriedades anfifílicas capazes de interagir com os fosfolípides das membranas celulares e organelas citoplasmáticas. Incluem a cloroquina e seus derivados, a amiodarona e o perexileno (não disponível em nosso meio). Menor capacidade anfifílica e neuromiotoxicidade menos expressiva ocorrem com a imipramina, a clorciclizina e a zimelidina. A colchicina pode inibir hidrolases lisossomais como parte de seu efeito sobre a tubulina.

As drogas anfifílicas interagem com os grupos aniônicos dos fosfolípides e os complexos droga-fosfolípide resistem à digestão lisossomal e são reagrupados em estruturas lamelares ou reticulares chamadas corpúsculos mielinóides. O depósito desses corpúsculos resultam, por sua vez, em acúmulo lisossomal em vários tecidos. Curiosamente, pacientes com erros inatos do armazenamento lisossômico não estão sob maior risco para a neuromiotoxicidade dessas drogas.

A miotoxicidade induzida por essas drogas compartilha os mesmos achados histopatológicos básicos que aquela induzida pela cloroquina, a qual pode ser tomada como droga paradigma do grupo: vacúolos sarco- 
TABELA 1

Etiologias da rabdomiólise induzida por drogas

\begin{tabular}{|c|c|c|}
\hline Ácido e-aminocapróico & Doxepina & Loxapina \\
\hline Acetazolamida & Doxilamina & Meperidina \\
\hline P-aminosalicilato & Etretinato & Metadona \\
\hline Amitriptilina & Fenfluramina & Metaqualona \\
\hline Anfetaminas & Fenazona & Metformina \\
\hline Anfotericina B & Fenazopiridina & Molindona \\
\hline Anti-histamínicos H1 & Fenelzina & Morfina \\
\hline 5 -azacitidina & Fenformina & Moxalatam \\
\hline Barbitúricos & Fenotiazínicos & Oxprenolol \\
\hline Benzodiazepínicos & Fenilpropanolamina & Pemolina \\
\hline Biperideno & Fenitoína & Penfluridol \\
\hline Bloqueadores neuromusculares & Fósforo & Pentamidina \\
\hline Butirofenonas & Fluoroacetato & Perfenazina \\
\hline Carbenoxolona & Gentamicina & Primaquina \\
\hline Clofibrato e derivados & Glutetimida & Procainamida \\
\hline Cloroquina & Haloperidol & Propoxifeno \\
\hline Clortalidona & Halotano/anestésicos halogenados & Quinidina \\
\hline Colchicina & Hidrato de cloral & Salicilatos \\
\hline Corticosteróides & Hidroxizina & Simpaticomiméticos \\
\hline Diclorofenoxiacetato & Isoniazida & Teofilina \\
\hline Difenidramina & Isotretinoína & Tiotixeno \\
\hline Diuréticos de alça & Lítio & Trimetoprim-sulfametoxazol \\
\hline Diuréticos osmóticos & Lovastatina/inibidores HMG-CoA & Triexifenidil \\
\hline
\end{tabular}

plasmáticos, necrose e segmentação longitudinal das fibras.

Os compostos 4-aminoquinolínicos incluem a cloroquina, a hidroxicloroquina, a quinacrina e a primaquina $^{9,10}$. O quadro miotóxico da cloroquina, que requer uso prolongado e em doses elevadas, é de instalação lenta e inicia-se pelos músculos proximais dos membros inferiores e cintura pélvica, atingindo, na evolução, os músculos dos membros superiores e faciais. Pode associar-se cardiomiotoxicidade. As biópsias musculares mostram envolvimento preferencial das fibras tipo I e acúmulo vacuolar. Na microscopia eletrônica, são abundantes os corpúsculos mielinóides e curvilineares, que ultra-estruturalmente são semelhantes àqueles encontrados na lipofuscinose ceróide.

A amiodarona ${ }^{11}$ é a outra droga catiônica anfifílica mais freqüentemente envolvida em neuromiotoxicidade e, assim como a cloroquina, causa também neuropatia periférica. O hipotireoidismo é outro efeito adverso e que deve ser considerado no paciente com fraqueza 
durante seu uso. Estudos experimentais têm demonstrado maior acúmulo de corpúsculos mielinóides em músculos desnervados e sua toxicidade neuromuscular poderia muito apropriadamente ser considerada uma neuromiopatia tóxica na qual predominam os efeitos deletérios sobre o axônio periférico.

\section{Miopatias antimi crotubulares}

Tanto a colchicina quanto a vincristina ${ }^{12}$, por mecanismos diferentes, alteram a função microtubular, resultando em função lisossomal anormal e acúmulo de vacúolos autofágicos.

A neuromiopatia pela colchicina exige uso prolongado, mesmo com doses usuais. É mais comum em pacientes idosos ou com função renal limítrofe. Alguns pacientes desenvolvem, associadamente ao quadro neuropático, paresia proximal e aumento leve a moderado da CK. O quadro miopático, ao contrário da neuropatia periférica, usualmente reverte de pronto com a suspensão da droga.

Em modelos animais, as alterações mais precoces ocorrem na região intermiofibrilar, com acúmulo de vacúolos fosfatase-ácida positivos; mais tardiamente, as mesmas alterações aparecem na região subsarcolemal. O quadro final é semelhante ao descrito em humanos: miopatia vacuolar com acúmulo de lisossomos e vacúolos autofágicos, sem mionecrose. As alterações lisossômicas são secundárias ao efeito primário sobre a tubulina e o aparato microtubular.

A vincristina tem como neurotoxicidade periférica o principal efeito adverso neuromuscular. A miopatia clínica ocorre menos freqüentemente e também relacionada com o uso prolongado. Em modelos animais, as alterações iniciais consistem em corpúsculos esferomembranosos intermiofibrilares que são derivados de mitocôndrias e do retículo sarcoplasmático. A seguir, surge vacuolização e degradação das fibras musculares.

\section{Miopatias inflamatórias induzidas por drogas}

A miopatia inflamatória é uma das complicações imunomediadas induzidas pela D-penicilamina ${ }^{13}$, podendo ocorrer em qualquer período do tratamento independentemente da dose. Pode-se associar cardiomiotoxicidade. A recuperação é a regra, após a retirada da droga, embora possa ser lenta e exigir tratamento com corticosteróides.

A procainamida ${ }^{14}$ pode induzir uma miosite intersticial generalizada, isoladamente ou como parte da vasculite sistêmica e da síndrome lúpica que ela induz. As biópsias musculares mostram infiltrado perivascular linfomacrofágico peri e endomisial, com pouca necrose de fibras. Em casos isolados, foi descrita miopatia inflamatória relacionada ao uso de fenitoína e levodopa ${ }^{15}$, muito provavelmente por reação de hipersensibilidade, com febre, linfonodomegalia, eosinofilia e arteriolite compondo o quadro clínico.

A síndrome de eosinofilia-mialgia foi descrita no início dos anos 80 e, logo após, relacionada com o uso de preparações de triptofano ${ }^{16,17}$ contendo aldeído, 3fenil-aminoalanina e outros contaminantes. A desordem caracteriza-se por início agudo ou subagudo de mialgias, fadiga e eosinofilia acentuada, usualmente acima de $2.000 \mathrm{~mm}^{3}$. A pele, o tecido subcutâneo, as fáscias musculares, os músculos e os nervos são as estruturas mais afetadas. As manifestações mais comuns incluem febre, rash maculopapular, mialgias, fadiga, câimbras, paresia proximal e parestesias distais; menos comumente ocorrem pneumonite, artrite, hepatomegalia e linfonodomegalia generalizada. Os sinais variam conforme a doença se apresente primariamente como miosite, fasciite, neuropatia periférica ou uma combinação das três. A biópsia muscular mostra infiltrado inflamatório perimisial e na fáscia, vasos, nervos intramusculares e fusos neuromusculares, poupando o endomísio. A presença de linfócitos T, de macrófagos ativados, a pobreza ou a ausência de linfócitos B e a deposição de imunocomplexos sugerem uma resposta celular e não-humoral.

A associação de cimetidina, leuprolide e propiltiouracila com polimiosite parece ser fortuita, e não há comprovação definitiva de relação causal.

\section{Miopatias induzidas por hipocalemia}

Os efeitos adversos da hipocalemia ${ }^{18,19}$ sobre o músculo são múltiplos e incluem alterações no transporte iônico, diminuição da síntese e armazenamento de glicogênio e diminuição do fluxo sangüíneo, sem o aumento compensatório induzido pelo exercício. O potássio é necessário à glicogenólise e à síntese de fosfocreatina. Modelos in vitro e in vivo não mostraram, contudo, que a geração de energia seja comprometida, mesmo naquelas doses que se acompanham de rabdomiólise. Durante a contração muscular e o exercício, os íons $\mathrm{K}^{+}$são liberados para o interstício e, provavelmente, causam vasodilatação; a rabdomiólise induzida pela hipocalemia poderia, assim, ser causada por isquemia do músculo.

As drogas indutoras de hipocalemia incluem anfotericina $\mathrm{B}$, corticosteróides, diuréticos de alça e 
diuréticos osmóticos, gentamicina, laxativos e álcalis antiácidos orais (uso abusivo), simpaticomiméticos (principalmente b), teofilina e vitamina B12.

O quadro clínico é variável, a maioria dos pacientes desenvolve quadriparesia proximal transitória, com reflexos e sensibilidade preservados. Jejum prolongado, temperatura ambiente excessiva e exercício potencializam os efeitos da hipocalemia sobre o músculo. Os níveis de CK estão usualmente aumentados de forma marcada. As biópsias mostram achados leves, como edema e vacuolização de fibras, de forma multifocal e esparsa. Nos casos mais intensos ocorrem mionecrose, miofagocitose e fenômenos de regeneração acompanhados de mioglobinúria. O quadro clínico e, mesmo em certa medida, o histopatológico são revertidos com a reposição de potássio.

\section{Miopatia mitocondrial induzida por zidovudina}

A zidovudina ${ }^{20,21,22}$ causa uma miopatia dolorosa progressiva, com atrofia importante e níveis de CK normais ou pouco elevados. A droga deve sua ação antiretroviral ao agir como um falso substrato para a transcriptase reversa. O mesmo também ocorre para as polimerases mitocondriais, o que parece estar na base de sua miotoxicidade.

A diferenciação com a miopatia do HIV pode ser impossível em alguns casos, apesar de alguns considerarem as alterações histopatológicas capazes de diferenciá-las. Dalakas et al. ${ }^{22}$ encontraram fibras ragged red (RRF) em biópsias de pacientes recebendo zidovudina e, muito raramente, na miopatia do HIV. O número dessas fibras correlacionava-se com a gravidade da miopatia, e os autores propuseram que a miopatia seria decorrente da inibição da DNA-gama polimerase, responsável pela replicação do DNA mitocondrial. Contudo, Simpson et al. ${ }^{21}$ observaram ocorrência muito rara de RRF típicas, apesar do achado comum de diversas alterações mitocondriais menores à microscopia eletrônica em pacientes, recebendo ou não zidovudina. Assim, em seus pacientes, a ocorrência de RRF e as alterações mitocondriais não permitiram distinguir a miopatia própria do HIV daquela induzida pela zidovudina.

\section{MIOPATIA DO DOENTE GRAVE}

Desde os anos 70, desordens neuromusculares têm sido reconhecidas como causas de fraqueza generalizada e dependência prolongada de respiradores em pacientes gravemente enfermos.

Uma polineuropatia que se desenvolve no contexto de sepse e falência de múltiplos órgãos, usualmente denominada polineuropatia do doente crítico (PDC), foi primeiramente descrita por Bolton et al. ${ }^{23} \mathrm{O}$ principal fator predisponente para essa polineuropatia é a síndrome de resposta inflamatória sistêmica (SRIS), na maioria das vezes desencadeada por sepse. Uma síndrome miopática, ocorrendo também no contexto do paciente crítico, vem recebendo atenção crescente nos últimos anos. Essa síndrome, que provavelmente permanece subdiagnosticada diante da PDC, é usual, mas não obrigatoriamente associada ao uso concomitante de corticosteróides em altas doses e de bloqueadores neuromusculares não-despolarizantes. A diferenciação entre as duas condições não é fácil e há grande variabilidade na incidência, em parte devido à ausência de critérios clínicos rígidos. Um estudo prospectivo de Witt et al. ${ }^{24}$ demonstrou anormalidades ao exame de neurocondução em cerca de $70 \%$ dos doentes com SIRS/sepse. Estudos prospectivos subseqüentes mostraram números muito divergentes. Lacomis et al. ${ }^{25}$ avaliaram prospectivamente 92 pacientes graves, a maioria sépticos, num período de 5 anos e encontraram envolvimento primariamente miopático em $42 \%$ e PDC em apenas $13 \%$ deles.

Essa síndrome miopática tem recebido as denominações de miopatia do doente crítico (MDC), miopatia quadriplégica aguda, miopatia aguda da unidade de terapia intensiva e miopatia rapidamente progressiva com deficiência de miosina.

A patogênese permanece controversa. Uma miopatia similar pode ser produzida em modelos animais com o uso de altas doses de dexametasona após a desnervação do músculo-alvo ${ }^{26}$. Os receptores para esteróides parecem sofrer um processo de up-regulation em músculos desnervados ou cronicamente imobilizados, e isso tem implicações também na doença clínica. Assim como nesta, a microscopia eletrônica mostra a perda dos filamentos de miosina. Supõe-se que o bloqueio neuromuscular prolongado, criando um estado de desnervação funcional, torne o músculo mais vulnerável aos efeitos dos corticosteróides. Permanece incerto o grau de contribuição que a PDC possa ter nessa síndrome e há relatos descritos nos quais ela ocorreu independentemente do uso de bloqueadores neuromusculares ${ }^{27,28}$.

Os pacientes com MDC apresentam-se com fraqueza generalizada ${ }^{29,30}$, tanto distal quanto proximal, ocasionalmente ocorrendo envolvimento dos músculos faciais e oculares extrínsecos. A sensibilidade está preservada e os reflexos normais ou reduzidos em 
paralelo ao grau de fraqueza. O prognóstico é favorável e a força retorna ao normal em um a três meses na maioria dos pacientes.

A biópsia muscular mostra perda de reação à miosina em ATPase ácida, e a microscopia eletrônica confirma a perda de filamentos de miosina. Em uma minoria dos pacientes predomina necrose. Em muitos casos, a única anormalidade pode ser a atrofia de fibras, principalmente de fibras tipo 2. Esses diferentes padrões patológicos podem representar um espectro de gravidade do mesmo mecanismo patofisiológico.

Os estudos de neurocondução ${ }^{31,32,33}$ mostram diminuição da amplitude dos potenciais de ação musculares compostos, estando a neurocondução sensitiva e o teste de estímulo repetitivo normais. O exame eletromiográfico revela atividade de fibrilação esparsa e potenciais de unidades motoras de duração e amplitude reduzidas, com recrutamento miopático típico. Entretanto, um grupo extenso de pacientes exibe características eletrofisiológicas tanto da MDC quanto da PDC. Um grande número de pacientes em unidades de terapia intensiva são afetados por sepse ou SRIS. Muitos deles recebem corticosteróides, bloqueadores neuromusculares ou ambos. Há vários casos, relatados nos anos 90 , nos quais a $\mathrm{MDC}^{34,35}$ não esteve relacionada ao uso daquelas drogas e, em contrapartida, muitos casos rotulados como PDC que as receberam. Há, portanto, uma grande sobreposição dos principais fatores predisponentes, e a história clínica, isoladamente, não permite diferenciar as duas condições. A situação é complicada devido à limitação do exame eletrofisiológico no ambiente das unidades de terapia intensiva (principalmente da neurocondução sensitiva e do exame de agulha) e à gravidade dos pacientes, os quais invariavelmente não estão em condições de colaborar adequadamente. A estimulação direta do músculo e a obtenção do potencial de ação muscular por tal técnica permitem contornar essas dificuldades e auxiliam no diagnóstico diferencial desse grupo heterogêneo de pacientes ${ }^{31,33}$. Na MDC, mas não na PDC, os potenciais obtidos com a estimulação direta do músculo são tão reduzidos quanto aqueles obtidos com a estimulação do nervo. Com esta técnica, Rich et al. ${ }^{31}$ identificaram a MDC em pacientes inicialmente rotulados como tendo "PDC de predomínio motor".

O músculo está eletricamente hipo ou inexcitável na MDC. A melhora clínica correlaciona-se com a recuperação da excitabilidade do sarcolema, indicando que a fraqueza na MDC é principalmente resultado dessa hipoexcitabilidade, embora a perda de filamentos de miosina e a atrofia de fibras também contribuam. Essa alteração de excitabilidade explica a severa redução dos potenciais de ação musculares na presença de morfologia muscular subnormal, e o mecanismo é semelhante ao observado nas paralisias periódicas. Na MDC parece depender da redução dos canais de $\mathrm{Na}+{ }^{36,37}$. A relação entre a inexcitabilidade do sarcolema e os achados patológicos permanece especulativa. Provavelmente, essa alteração é um evento precoce que ocorre na ausência de alterações morfológicas. Nos casos mais avançados, somam-se atrofia e perda de filamentos de miosina, e a necrose pode ser o resultado final nos casos mais graves.

\section{DROGAS, TRANSMISSÃO NEUROMUSCULAR E MIASTENIA GRAVIS}

Várias drogas e toxinas são capazes de interferir adversamente na transmissão neuromuscular (TNM), podendo ser categorizadas de diferentes maneiras. Uma forma útil e funcional baseia-se nas várias etapas da transmissão neuromuscular e em seus mecanismos subjacentes: alterações em canais iônicos voltagemdependentes ( $\mathrm{Na}, \mathrm{Ca}$ e $\mathrm{K}$ ), liberação de acetilcolina (ACh), mediada pelo $\mathrm{Ca}$, atividade da $\mathrm{ACh}$ e fatores da membrana pós-sináptica. Assim, três áreas podem ser delimitadas: o nervo periférico/terminal axônico, o espaço sináptico e a membrana pós-sináptica com os receptores de ACh (AChR).

Nosso conhecimento sobre a ação dessas drogas na TNM é limitado pelas lacunas que ainda persistem na compreensão dos mecanismos da interação nervomúsculo. Isso é particularmente importante no mecanismo de ação dos diversos antibióticos. Ainda, muito do nosso conhecimento nessa área deriva de relatos clínicos de casos isolados ou de estudos clínicos pouco detalhados. Na maioria desses estudos, não se empregaram testes neurofisiológicos, e poucas conclusões quanto ao sítio de distúrbio da TNM podem ser inferidas. Por outro lado, estudos bem controlados em modelos animais não necessariamente podem ser transpostos para a situação clínica em humanos.

\section{Drogas com ação pré-si náptica}

\section{Ação nos canais de cálcio (Ca)}

Os canais de Ca voltagem-dependentes são abertos durante a despolarização do terminal axonal. A entrada de Ca facilita a liberação de ACh das vesículas présinápticas. Várias drogas podem alterar a condutância 
do $\mathrm{Ca}$, incluindo-se os diversos bloqueadores dos canais de Ca. Apesar de essas drogas não causarem efeitos adversos na TNM em indivíduos normais, há vários relatos de exacerbação de pacientes miastênicos ou prolongamento da ação de bloqueadores neuromusculares com o uso de diltiazem e verapamil ${ }^{38}$.

A administração de sais de magnésio pode, adversamente, afetar a TNM ao inibir competitivamente a entrada de Ca no terminal axonal e inibir a liberação pré-sináptica de ACh. Situações clínicas potenciais incluem a doença hipertensiva específica da gravidez e o uso abusivo de laxativos ${ }^{39}$. A exacerbação de miastenia também é descrita ${ }^{40}$.

Diversos antibióticos têm também essa capacidade. Os aminoglicosídeos produzem um bloqueio neuromuscular por competição com o $\mathrm{Ca}$ e, conseqüentemente, diminuição da liberação dos quanta de $\mathrm{ACh}$ e, muito secundariamente, por mecanismos desconhecidos, ao estabilizarem a membrana pós-sináptica. O bloqueio é antagonizado por sais de cálcio, mas apenas pobremente com agentes anticolinesterásicos. Uma revisão de 83 $\operatorname{casos}^{41}$, em pacientes miastênicos e não-miastênicos, implicou a neomicina como o principal agente. Em ordem decrescente da potência de bloqueio neuromuscular, teríamos: neomicina, canamicina, amicacina, gentamicina, estreptomicina e tobramicina. A administração de altas doses por via intrapleural (uso raro atualmente) ou intraperitoneal parece ser particularmente arriscada, embora o bloqueio ocorra com as doses usuais por via intravenosa ou intramuscular e mesmo oral (esterilização da flora intestinal).

Muitos dos efeitos adversos dos corticosteróides e a piora inicial que podem induzir na miastenia parecem ser devidos a efeitos pré-sinápticos na TNM. Parecem atuar no terminal axonal diretamente, causando despolarização anormal, que eventualmente leva à redução da liberação de ACh por alterações da condutância do $\mathrm{K}$ e, secundariamente, por efeitos diretos na placa motora $^{42,43}$. Os efeitos imediatos de altas doses de prednisona na TNM e nos títulos de anticorpos antiAChR foram estudados em 27 pacientes miastênicos ${ }^{44}$. Decremento significativo na contração voluntária máxima, mas não na amplitude do potencial de ação muscular, pode ser observado uma hora após a administração, e os autores especulam que decorra de dissociação nervo-músculo em adição ao bloqueio de íons no AChR.

A azatioprina e a teofilina, ao inibirem a enzima fosfodiesterase, aumentam a concentração de AMP cíclico no terminal pré-sináptico e, assim, a liberação de quanta de ACh. Os derivados imidazólicos exercem efeito deletério na TNM por ação oposta.

\section{Drogas com ação pré e pós-si náptica}

As polimixinas e a colistina podem produzir piora clínica em pacientes miastênicos, e o mecanismo parece ser principalmente pós-sináptico. Tanto aminoglicosídeos, tetraciclinas, lincomicina e clindamicina podem, em altas doses, aumentar a estabilidade da membrana pós-sináptica e reduzir a geração de potenciais de placa por mecanismos pouco caracterizados ${ }^{45,46}$.

A procainamida pode piorar quadros miastênicos por mecanismos desconhecidos pré e pós-sinápticos. Estudos in vitro mostram bloqueio fraco e reversível da TNM, possivelmente resultante de alterações da interação entre a ACh e seu receptor ${ }^{47}$.

Relatos muito antigos já correlacionavam a fenitoína e a trimetadiona ${ }^{48,49}$ com a exacerbação de miastenia. Estudos em animais demonstram que a fenitoína induz tanto a redução do potencial de ação pré-sináptico quanto a redução da sensibilidade dos AChR. A trimetadiona parece ter efeito similar, entretanto anticorpos antinucleares podem ser induzidos por essa droga, sugerindo um mecanismo auto-imune.

Os bloqueadores $\beta$-adrenérgicos ${ }^{50}$ interferem pré e pós-sinapticamente na TNM, e vários casos de exacerbação de miastenia, mesmo com o uso de preparações oculares, encontram-se descritos. Fraqueza e fadigabilidade leves podem ocorrer precocemente no tratamento com carbonato de lítio ${ }^{51} \mathrm{e}$, gradualmente, melhoram após duas a quatro semanas. In vitro, a droga reduz o número de AChR e também compete com o Ca no terminal présináptico, tendo efeitos indiretos na condutância do K.

A d-penicilamina deve toda sua ação como causadora de miastenia à indução de anticorpos anti-AChR. Tais anticorpos ocorrem em mais de $90 \%$ dos pacientes com miastenia por ela induzida ${ }^{52}$, e não parece haver qualquer efeito direto na TNM. A maioria dos pacientes relatados utilizava a droga para tratamento de doença reumatóide, embora outras condições, como a doença de Wilson, a cirrose biliar primária e a esclerodermia, também estejam presentes. Dois mecanismos têm sido propostos: a droga ao combinar-se com o AChR agiria como hapteno, alterando sua antigenicidade e induzindo a produção de anticorpos. Um segundo mecanismo surgiu da observação de que a droga aumenta a produção de prostaglandina E1, a qual se acumularia nos $\mathrm{AChR}^{53}$. Devido à ocorrência comum de pacientes com doenças auto-imunes nos quais o uso concomitante de penicilamina induziu miastenia, foi aventado que a droga poderia apenas precipitar a miastenia idiopática. Várias linhas de evidência contrariam essa hipótese. O curso clínico da miastenia induzida por penicilamina caracteriza-se por remissão completa, no primeiro ano após sua 
suspensão, em mais de 2/3 dos pacientes. Esse número é muito superior ao usualmente visto na miastenia idiopática e a maioria dos pacientes não necessita de anticolinesterásicos ou corticosteróides por tempo prolongado. A tipagem do HLA muito raramente mostra o halótipo B8, que ocorre em mais de $80 \%$ das mulheres com miastenia idiopática.

Diversas outras drogas têm sido mais raramente associadas com a indução ou a exacerbação de quadros miastênicos, existindo, para a maioria delas, relatos de casos esparsos e isolados: ciprofloxacina, ampicilina, imipenema-cilastatina, eritromicina, triexifenidila, propafenona, cloroquina, acetazolamida, D-carnitina, interferon-alfa (indução de casos de novo, predominando fraqueza bulbar e da musculatura ocular), levonorgestrel, quinidina, nicotina (patches transdérmicos) e os agentes de contraste, ácido iotalâmico e diatrizoato de meglumina (Tabela 2).

Além dessas toxicidades, discutir-se-á em seguida três condições clínicas que dependem basicamente de drogas desencadeantes para se manifestarem, podendo ser consideradas doenças farmacogenéticas: as porfirias, a síndrome neuroléptica maligna e a hipertermia maligna.

\section{PORFIRIAS}

São desordens hereditárias da biossíntese do heme, causadas por defeitos enzimáticos específicos e classificadas em hepáticas ou eritropoiéticas, segundo o sítio de sobreprodução e acúmulo do precursor porfirínico. As porfirias eritropoiéticas e a porfiria hepática por deficiência de URO-descarboxilase - a porfiria cutanea tarda - cursam basicamente com fotossensibilidade, carecendo de manifestações neuromusculares.

As porfirias hepáticas com repercussão neurológica incluem três desordens autossômicas dominantes - a porfiria aguda intermitente (deficiência de hidroximetilbilano sintetase, HMB-sintetase, anteriormente chamada profobilinogênio deaminase), a coproporfiria hereditária (deficiência de COPRO-oxidase) e a porfiria variegada (deficiência de proto-oxidase) - e uma raríssima desordem autossômica recessiva, a porfiria por deficiência de ALA-deidratase. Tanto o chumbo quanto a succinilacetona, que se acumula na tirosinemia familiar, inibem a enzima ALA-deidratase e podem cursar com manifestações que simulam as das porfirias agudas. Assim, a intoxicação pelo chumbo e a tirosinemia familiar devem ser consideradas no diagnóstico diferencial das porfirias hepáticas.
As porfirias podem ser consideradas doenças ecogenéticas, nas quais a conjunção de fatores ambientais, fisiológicos e genéticos é necessária para a produção das manifestações clínicas. A maioria dos heterozigotos permanece clinicamente silentes até que surja um evento ambiental desencadeante. Esteróides gonadais endógenos (por exemplo, na gravidez) ou exógenos, diversas drogas, álcool, jejum prolongado, desnutrição e infecções são os fatores precipitantes mais comuns. Como drogas são o principal fator ambiental e podem, muito apropriadamente, serem consideradas doenças farmacogenéticas ${ }^{55}$.

Devido à multiplicidade de drogas existentes, é extremamente difícil predizer qual se associa ou não ao risco e à intensidade deste. Algumas generalizações puderam, contudo, ser estabelecidas ao longo dos anos. As drogas especialmente implicadas são aquelas indutoras de oxidação pelo citocromo P450, que induzem o aumento da produção de ácido 5-aminolevulínico, as drogas de alta lipossolubilidade, aquelas com o grupo alil, o núcleo básico dos barbitúricos e os esteróides (andrógenos, estrógenos e progestágenos sintéticos) $)^{55,56}$.

Os barbitúricos e as sulfonamidas são drogas obrigatoriamente contra-indicadas e consistentemente induzem exacerbações. Mais difíceis de interpretar são os relatos em casos isolados ou em número muito limitado de pacientes, principalmente quando essas mesmas drogas foram usadas com segurança em outros pacientes. Jejum prolongado ou uma intercorrência clínica, como doenças infecciosas, podem precipitar exacerbações, e muitos relatos do efeito de determinadas drogas podem ser atribuídos a outros eventos ambientais.

No intuito de resolver esses dados conflitantes, várias abordagens laboratoriais foram desenvolvidas, como estudos em ratos com porfiria (deficiência de ALA deidratase ou HMB-sintetase) quimicamente induzida, em cultura de hepatócitos de embrião de galinha, e a avaliação da atividade da HMB-sintetase em eritrócitos. Entretanto, o metabolismo do heme e dos diversos compostos pirrólicos varia profundamente nas diferentes espécies e mesmo entre espécies muito afins, como ratos e camundongos. Muitas drogas sabidamente porfirogênicas em humanos não tiveram sua porfirogenicidade confirmada em culturas de embrião de galinha. A interpretação dos dados obtidos com tais abordagens pode ser facilitada, comparando-se o efeito de drogas sabidamente indutoras, como a griseofulvina e o fenobarbital, com a droga em teste ${ }^{56,57}$.

Tendo essas limitações em vista, uma classificação de drogas seguras e indutoras é fornecida na tabela 3. 


\section{TABELA 2}

Drogas que causam indução ou exacerbação de miastenia

Droga

Indução (I) ou exacerbação (E)
Estudo neurofisiológico confirmativo
Melhora após suspensão

(S: $\operatorname{sim} ; N:$ não)

( $S: \operatorname{sim} ; N$ : não; NR: não-realizado)

\begin{tabular}{|c|c|c|c|}
\hline Ácido iotalâmico & $\mathrm{E}$ & NR & $\mathrm{S} / \mathrm{N}$ \\
\hline Aminoglicosídeos & $\mathrm{I} / \mathrm{E}$ & $S$ & $\mathrm{~S} / \mathrm{N}$ \\
\hline Ampicilina & $\mathrm{E}$ & NR & $\mathrm{S}$ \\
\hline Ciprofloxacina & $\mathrm{I} / \mathrm{E}$ & NR & $\mathrm{S} / \mathrm{N}$ \\
\hline Cloroquina & I & $\mathrm{N}$ & $\mathrm{S} / \mathrm{N}$ \\
\hline Corticosteróides & $\mathrm{E}$ & $\mathrm{N}$ & $\mathrm{S}$ \\
\hline D-carnitina & I & NR & $\mathrm{S}$ \\
\hline Diltiazem & $\mathrm{E}$ & $S$ & $S$ \\
\hline Diatrizoato de meglumina & $\mathrm{E}$ & NR & $\mathrm{S} / \mathrm{N}$ \\
\hline Eritromicina & $\mathrm{I} / \mathrm{E}$ & NR & $\mathrm{S}$ \\
\hline Fenitoína & $\mathrm{I} / \mathrm{E}$ & S & $\mathrm{S} / \mathrm{N}$ \\
\hline Imipenema-cilastatina & $\mathrm{E}$ & NR & $\mathrm{S}$ \\
\hline Interferon-alfa & I & NR & $\mathrm{Y}$ \\
\hline Levonorgestrel & $\mathrm{E}$ & $S$ & $\mathrm{~N}$ \\
\hline Lítio, carbonato & $\mathrm{I} / \mathrm{E}$ & $\mathrm{S}$ & $\mathrm{S} / \mathrm{N}$ \\
\hline Nicotina transdérmica & $\mathrm{E}$ & NR & $\mathrm{S}$ \\
\hline Procainamida & $\mathrm{I} / \mathrm{E}$ & NR & $S$ \\
\hline Propafenona & $\mathrm{E}$ & NR & $S$ \\
\hline Propranolol e outros $\beta$-bloqueadores & $\mathrm{I} / \mathrm{E}$ & $S$ & $\mathrm{~S} / \mathrm{N}$ \\
\hline Quinidina & I & $\mathrm{N}$ & $\mathrm{S}$ \\
\hline Trimetadiona & I & $\mathrm{S}$ & $\mathrm{N}$ \\
\hline Triexifenidila & $\mathrm{I} / \mathrm{E}$ & NR & $\mathrm{S}$ \\
\hline Verapamil & E & $S$ & $\mathrm{~S} / \mathrm{N}$ \\
\hline
\end{tabular}

\section{SÍNDROME NEUROLÉPTICA MALIGNA}

A síndrome neuroléptica maligna (SNM) foi descrita nos primeiros ensaios clínicos com o haloperidol no início dos anos 60. Apesar desses primeiros relatos, a condição permaneceu pouco reconhecida. A partir da década de 80, entretanto, aumentou o reconhecimento da condição, o que resultou na publicação de centenas de casos e várias revisões.

Apesar da SNM ser rara, o uso disseminado de neurolépticos pode fornecer um número absoluto de 
TABELA 3

Segurança das diversas drogas nas porfirias

Drogas indutoras

Drogas seguras

Drogas de ação indeterminada

\section{Antimicrobianos}

Dapsona
Griseofulvina
Pirazinamida
Sulfonamidas
Ácido nalidíxico
Eritromicina
Isoniazida
Quinolonas
Metronidazol

$\begin{array}{lll}\text { A } & \text { Penicilinas } & \text { A } \\ \text { A } & \text { Aminoglicosídeos } & \text { B } \\ \text { A } & \text { Cefalosporinas } & \text { B } \\ \text { A } & \text { Eritromicina } & \text { B } \\ \text { B } & \text { Primaquina } & \text { B } \\ \text { B } & & \\ \text { B } & & \\ \text { B } & & \\ \text { C } & \end{array}$

Agentes anestésicos/indutores de anestesia

\begin{tabular}{lllll}
\hline Barbituratos & A & Dietil-éter & A & Halotano \\
Alfaxalona & B & Óxido nítrico & A & Quetamina \\
Clorofórmio & B & Procaína & B & Alfentanil \\
Metoxiflurano & B & Ametocaína & C & \\
Enflurano & C & Bupivacaína & C & \\
Etomidato & C & & &
\end{tabular}

\section{Anticonvulsivantes}

\begin{tabular}{lllll}
\hline Barbituratos & A & Hidrato de cloral & A & Clonazepam \\
Carbamazepina & A & Brometos & B \\
Fenitoína & A & Lorazepam & Paraldeído \\
Succinimidas & A & & C & \\
\hline Sedativos/hipnóticos & & & A & Oxazepam \\
Glutetimida & A & Hidrato de cloral & Clordiazepóxido \\
Meprobromato & A & Lorazepam & Clonazepam \\
Flunitrazepam & B & & Diazepam
\end{tabular}

\section{Antipsicóticos}

$\begin{array}{ll}\text { Clorpromazina } & \text { A } \\ \text { Prometazina } & \text { A } \\ \text { Proloroperazina } & \text { A } \\ \text { Periciazina } & \text { B } \\ \text { Ciclizina } & \text { B } \\ \text { Trifluoperazina } & \text { B } \\ \text { Haloperidol } & \text { B }\end{array}$

\section{Antidepressivos}

Tranilcipromina

Pargilina

C Nortriptilina

C Lítio

A
B
B
B
B

B

Hormônios/antagonistas hormonais

\begin{tabular}{|c|c|c|c|}
\hline Estrógenos & $\mathrm{B}$ & Insulina & A $\quad$ Corticosteróides \\
\hline Andrógenos & $\mathrm{B}$ & Tiroxina & $\mathrm{B}$ \\
\hline Metirapona & $\mathrm{D}$ & & \\
\hline Sulfoniluréias & $\mathrm{A}$ & Biguanidas & $\mathrm{C}$ \\
\hline \multicolumn{4}{|c|}{ Drogas cardiovasculares } \\
\hline & & Digitálicos & A \\
\hline & & Adrenalina & B \\
\hline & & Aminas simpaticomiméticas & $\mathrm{B}$ \\
\hline & & Adenosina & $\mathrm{B}$ \\
\hline & & Nitratos & $\mathrm{B}$ \\
\hline
\end{tabular}




\section{Broncodilatadores}

Aminofilina/teofilina

Diuréticos

Furosemida

Clorpropamida

Outros tiazídicos

Espironolactona

$\begin{array}{lll}\text { B } & \text { Agonistas b2 } & \text { B } \\ \text { B } & \text { Bumetanida } & \text { B } \\ \text { B } & \text { Acetazolamida } & \text { D } \\ \text { C } & \text { Diazóxido } & \text { D } \\ \text { C } & & \end{array}$

\section{B}

B

D

\section{Anti-hipertensivos}

\begin{tabular}{llll}
\hline Alfametildopa & A & Betabloqueadores & A \\
Clonidina & D & Guanetidina & A \\
& & Reserpina & A \\
& & Labetalol & B \\
& & Inibidores ECA & D
\end{tabular}

\section{Anticoagulantes}

$\begin{array}{ll}\text { Dicumarínicos } & \text { A } \\ \text { Heparina } & \text { B }\end{array}$

\section{Analgésicos narcóticos}

\begin{tabular}{|c|c|c|c|}
\hline Pentazocina & A & $\begin{array}{l}\text { Morfina e derivados } \\
\text { Droperidol } \\
\text { Metadona } \\
\text { Propoxifeno }\end{array}$ & $\begin{array}{l}\mathrm{A} \\
\mathrm{A} \\
\mathrm{A} \\
\mathrm{A}\end{array}$ \\
\hline
\end{tabular}

\section{Antiinflamatórios}

Dipirona

Fenilbutazona e derivados

Ácido flufenâmico

Cetoprofeno

\section{Antigotosos}

\section{Anticolinesterásicos}

Bloqueadores neuromusculares

Pancurônio e outros não-despolarizantes

\section{Diversos}

Pirazolona

Dimenidrato

Metoclopramida

Bussulfano

Ciclofosfamida

Clorambucil

Cimetidina

Ouro

$\begin{array}{lll}\text { A } & \text { Aspirina } & \text { A } \\ \text { A } & \text { Ácido mefenâmico } & \text { B } \\ \text { B } & \text { Ibuprofeno } & \text { B } \\ \text { B } & \text { Indometacina } & \text { B } \\ & \text { Flurbiprofeno } & \text { B } \\ & \text { Naproxeno } & \text { B } \\ & \text { Paracetamol } & \text { B } \\ & \text { Fenoprofeno } & \text { C } \\ & \text { Sulindac } & \text { C }\end{array}$

$\begin{array}{ll}\text { Colchicina } & \text { B } \\ \text { Alopurinol } & \text { C }\end{array}$

Todos

A

B Succinilcolina

A

d-tubocurarina

B

$\begin{array}{ll}\text { A } & \text { Clorfeniramina } \\ \text { B } & \text { Difenidramina } \\ \text { B } & \text { Hioscina } \\ \text { C } & \text { Penicilamina } \\ \text { C } & \text { Propantelina } \\ \text { C } & \text { Vitaminas A-K } \\ \text { C } & \text { Domperidona } \\ \text { C } & \text { Clofibrato }\end{array}$

B

C

A
B
B
B
B
B
B
C
C

Categoria A: drogas reportadas por três ou mais autores especializados; categoria B: drogas reportadas por menos de três autores especializados; categoria C: drogas avaliadas apenas em ratos com porfiria quimicamente induzida; categoria D: drogas avaliadas apenas em cultura de hepatócitos de embrião de galinha; drogas de ação indeterminada: drogas nas quais a experiência clínica é discordante. 
casos elevado. Estimativas de incidência variam de $0,02 \%$ a $3,23 \%$, provavelmente refletindo diferentes critérios diagnósticos ${ }^{58}$. Os dados conjuntos de 16 estudos de incidência da SNM mostram 66 casos em 33.720 pacientes, o que fornece uma incidência de $0,2 \%{ }^{59}$

A ocorrência da síndrome não é influenciada por sexo ou idade e não é específica de nenhuma condição psiquiátrica, ocorrendo mesmo no tratamento de distúrbios do movimento ${ }^{59}$. Não parece também haver fatores de risco ambientais, embora a temperatura excessiva aumente o risco e o grau de rabdomiólise. O estado clínico do paciente pode também contribuir para o grau de rabdomiólise, principalmente a concomitância de desidratação, hipocalemia e jejum.

Existem apenas dois relatos de ocorrência familiar da $\mathrm{SNM}^{60,61}$, um deles em dois gêmeos com esquizofrenia indiferenciada e o outro em uma mãe e dois filhos com esquizofrenia catatônica. Pode haver alguma relação com a catatonia letal, uma condição familiar semelhante à $\mathrm{SNM}^{61}$.

Praticamente todos os antagonistas dopaminérgicos D2 foram associados com a SNM, incluindo-se não apenas os neurolépticos típicos e atípicos, mas também drogas afins, como a proclorperazina, o droperidol e a prometazina. $\mathrm{O}$ haloperidol é citado em praticamente metade dos casos, refletindo seu uso mais disseminado. A síndrome foi também relacionada à clozapina. Alguns estudos retrospectivos, mas não todos, mostraram relação com a dose e a potência do antipsicótico ${ }^{58,59,62}$. Os mais potentes e em doses elevadas carregam um risco um pouco mais elevado. A dose de ataque, e não a dose total, parece ser o fator mais importante ${ }^{63}$; doses elevadas dos agentes mais potentes, administradas em tempo muito curto e em formas de depósito (decanoato de haloperidol e flufenazina, principalmente), parecem, assim, carregar maior risco. Até $30 \%$ desenvolvem episódios subseqüentes quando re-expostos ao mesmo ou a outro neuroléptico ${ }^{64}$.

Clinicamente, a síndrome caracteriza-se pelos achados fundamentais de hipertermia, rigidez, disautonomia e alterações mentais. A SNM pode muito adequadamente ser descrita como uma hipertermia induzida por drogas. É o resultado de disfunção dos mecanismos termorreguladores hipotalâmico-diencefálicos. Rigidez generalizada ocorre em virtualmente todos os pacientes; tremor e mioclonias generalizadas ocorrem freqüentemente, e menos comumente distonia focal ou generalizada e opistótono. Juntamente com a hipertermia, a atividade muscular excessiva e mantida, daí decorrente, estão na base da rabdomiólise. Elevação da CK ocorre em mais de $90 \%$ dos pacientes e mioglobinúria, em $67 \%$, podendo evoluir para necrose muscular franca. Jejum e desidratação aumentam o risco de mionecrose ${ }^{64}$.

\section{HIPERTERMI A MALIGNA}

A suscetibilidade à hipertermia maligna (HM), uma desordem muscular autossômica dominante, é uma das principais causas de morte relacionada com a anestesia. É desencadeada pelos anestésicos halogenados e pelos bloqueadores neuromusculares despolarizantes, originando-se da liberação excessiva de cálcio $(\mathrm{Ca})$ do retículo sarcoplasmático (RSP).

A síndrome pode ser desencadeada por qualquer uma das drogas citadas, mas é mais abrupta com a succinilcolina. O músculo esquelético abruptamente aumenta seu consumo de oxigênio e a produção de lactato, resultando em rigidez, em hipertermia rapidamente progressiva, em acidose metabólica e em aumento do drive simpático em resposta à inabilidade em controlar as concentrações do $\mathrm{Ca}$ sarcoplasmático. Ocorre liberação muscular de potássio, Ca ionizado, CK, mioglobina e rabdomiólise. É uma complicação comum.

A base genética é heterogênea, mas na maioria dos indivíduos deve-se a uma das várias mutações no canal de Ca do RSP, conhecido como receptor rianodínico (RRi) e mapeado no locus $19 \mathrm{q} 13.1^{65,66}$, podendo ser confirmada com os testes de contratura in vitro com cafeína e halotano. Uma síndrome praticamente idêntica ocorre em suínos, e os modelos daí obtidos forneceram muitas das informações sobre a síndrome. A liberação de Ca do RSP normal é iniciada pela despolarização e ativação dos túbulos T. Há liberação, inicialmente, restrita de $\mathrm{Ca}$, que em uma segunda fase induz per se a liberação maciça deste, a partir do $\operatorname{RSP}^{67,68}$. As alterações funcionais e morfológicas dos canais de cálcio do RSP, o receptor rianodínico, estão nas base das síndromes humana e porcina, que respondem de forma anormal, com liberação exagerada de $\mathrm{Ca}$ quando expostos às drogas citadas. $\mathrm{O}$ papel das alterações do receptor diidropiridínico dos túbulos $\mathrm{T}$, que conectam este ao RRi, e da deficiência de inositoltrifosfatase carece de confirmação tanto em humanos quanto em suínos $^{69}$. A succinilcolina parece desencadear a HM pelos seus efeitos diretos na junção neuromuscular, enquanto o halotano e os anestésicos pela sua ação no RSP (em doses terapêuticas e mesmo em indivíduos normais), aumentam a liberação de Ca do RSP. Em humanos, diferentemente dos suínos, episódios de HM parecem apenas ser desencadeados por tais agentes. Entretanto, as situações clínicas não relacionadas com a anestesia foram relatadas ${ }^{69}$. Em famílias suscetíveis 
pode haver uma incidência anormalmente elevada de morte súbita e miocardiopatia.

A HM está estreitamente relacionada à miopatia central core e ambas podem ser vistas como variantes alélicas do mesmo defeito genético. Outras miopatias relacionadas à HM são a síndrome de King-Denborough (miopatia e malformações musculoesqueléticas congênitas múltiplas) e a miopatia de Barnes. As distrofinopatias ligadas ao X estão indiretamente relacionadas e as fibras musculares desses pacientes podem não tolerar as alterações súbitas desencadeadas pela succinilcolina e pelos anestésicos ${ }^{68,69}$. A relação com as miotonias distróficas e não-distróficas e com a deficiência de miofosforilase não foram clinicamente comprovadas. A succinilcolina pode induzir a miotonia generalizada, mas não a síndrome de $\mathrm{HM}$, em pacientes com miotonia congênita e, mais raramente, na doença de Steinert e na paralisia periódica hipercalêmica. Nos pacientes com rigidez masseterina induzida por succinilcolina, recentemente relacionada a mutações na subunidade alfa do canal de sódio sarcoplasmático ${ }^{70,71}$, até $1 / 4$ exibem testes de contratura in vitro positivos.

\section{SUMMARY}

Peripheral nervous system drug induced toxicity: toxic myopathy, myasthenia gravis, porphyrias, neuroleptic malignant syndrome, hyperthermia malignant

Multiple drugs have been implicated to some degree in muscular damage or dysfunction of neuromuscular transmission. The exact manner in which drugs result in muscle diseases is highly diverse and depends on the substance. Exogenous substances may have either primary or secundary adverse effects on muscle tissue.

The authors also presented a brief revision of three conditions with neuromuscular dysfunction which may be considered farmacogenetic in nature: the porphyrias, neuroleptic malignant syndrome and malignant hyperthermia.

\section{KEYWORDS}

Myopathy, drugs, toxicity.

\section{Referências}

1. Curry SC, Cheng D, Connor D. Drug and toxin induced rhabdomyolysis. Ann Emerg Med, 18:1068-1083, 1989.

2. Bradford RH, Shear CC, Chemos NA, Dujovine C, Downton $\mathrm{M}$ et al. Expanded Clinical Evaluation of Lovastatin (EXCEL) Study results. Efficacy in modifying plasma lipoproteins and adverse effects in 8245 patients with moderate hypercholesterolemia. Arch Intern Med, 151:43-49, 1991.

3. Scandinavian Simvastatin Survival Study Group. Randomised trial of cholesterol lowering in 4444 patients with coronary heart disease: the Scandinavian Simvastatin Survival Study (4S). Lancet, 344:1383-1389, 1994.

4. Frick $\mathrm{MH}$, Elö O, Haapa $\mathrm{K}$, Heinonem $\mathrm{H}$, Heinsalmi $\mathrm{H}$ et al. Helsinki Heart Study: primary prevention trial with gemfibrozil in middle-aged men with dyslipidemia. Safety of treatment, changes in risk factors and incidence of coronary heart disease. N Engl J Med, 317:1237-1245, 1987.
5. Ayanion JZ, Fuchs CS, Stone RM. Lovastatin and rhabdomyolysis. Ann Intern Med, 109:682-686, 1988.

6. Magarian GJ, Lucas LM, Colley C. Gemfibrozil-induced myopathy. Arch Intern Med. 151:1873-1879, 1991.

7. Letin SC, Anderson CF. Nicotinic-acid associated myopathy; a report of three cases. Am J Med, 86:481, 1989.

8. Knitzer $\mathrm{RH}$, Needman BW. Musculoskeletal syndromes associated with treatment of acne. Semin Arthritis Rheumatol, 20:247-251, 1991.

9. Neville HE, Maunder-Sewry CA, McDougall. Chloroquineinduced cytosomes with curvilinear profiles in muscle. Muscle Nerve, 2:376-382, 1979.

10. Tagerud S, Jimanová I, Libelius R. Biochemical and ultrastructural effects of chloroquine on horseradish peroxidase uptake and lysosomal enzyme activities in innervated and denervated mouse skeletal muscle. J Neurol Sci, 75:159-166, 1986.

11. Roth F, Itabashi H, Louie J. Amiodarone toxicity - myopathy and neuropathy. Am Heart J, 119:1225-1229, 1990.

12. Kuncl RW, Wiggins VW. Toxic myopathies. Neurol Clin 6:593-612, 1988.

13. Bradley WG, Lassman LP, Pearce GW, Walton JN. The neuromyopathy of vincristine in man - clinical, electrophysiological and pathological studies. J Neurol Sci, 10:106-111, 1990

14. Halla JT, Fallahi S, Koopman WJ. Penicilamine-induced myositis in patients with rheumatoid arthritis. Arthritis Rheum, 29:560-565, 1986.

15. Lewis CA, Boheimer N, Rose P, Jackson G. Myopathy after short term administration of procainamide. $\mathrm{Br}$ Med $\mathrm{J}$ 292:593-598, 1986

16. Wolf S, Goldberg LS, Verity MA. Neuromyopathy and periarteriolitis in a patient receiving levodopa. Arc Intern Med, 136:1055-1057, 1976.

17. Hertzman P, Blevins WL, Mayer B. Association of the eosinophilia-myalgia syndrome with ingestion of tryptophan. N Engl J Med, 322:869-876, 1990.

18. Emslie-Smith AM, Engel AG, Duffy J, Bowles CA. Eosinophilia-myalgia syndrome: immunocytochemical evidence for a T-cell mediated immune effector response. Ann Neurol, 29:524-534, 1991.

19. Comi G, Testa D, Cornelio F. Potassium depletion myopathy - a clinical and morphological study of six cases. Muscle Nerve, 8:17-24, 1985.

20. Knochel P. Neuromuscular manifestations of electrolyte disorders. Am J Med 75:521- 530, 1982.

21. Mihiri C, Baudrimont, Bonne G. Zidovudine myopathy - a distinctive disorder associated with mitochondrial dysfunction. Ann Neurol, 29:606-612, 1991.

22. Simpson DM, Citak KA, Godfrey M, Godbold J, Wolfe DE. Myopathy associated with human immunodeficiency virus and zidovudine - can their effects be differenciated? Neurology, 43:971-976, 1993.

23. Dalakas MC, Illa I, Pezeshkpour GH. Mitochondrial myopathy caused by long-term zidovudine therapy. N Engl J Med, 322:1098-1105, 1990.

24. Bolton CF, Gilbert JJ, Hahn AF, Sibbald WJ. Polyneuropathy in critically ill patients. J Neurol Neurosurg Psychatry, 47:1223-1231, 1984.

25. Witt NJ, Zochodone DW, Bolton CF. Peripheral nerve function in sepsis and multiple organ failure. Chest, 99:176, 1991.

26. Lacomis D, Petrella JT, Giuliani MJ. Causes of neuromuscular weakness in the intensive care unit - a study of ninety-two patients. Muscle Nerve, 21:610-622, 1998.

27. Rouleau G, Karpati G, Carpenter S. Glucocorticoid excess induces peripheral depletion of myosin in denervated skeletal muscle fibers. Muscle Nerve, 10:428-434, 1987. 
28. Sheq JH, Shafiq AS, Shutta HS. Acute myopathy with selective loss of myosin filaments. Neurology, 29:100-106, 1979.

29. Knox AJ, Mascie-Taylor BH, Muers MF. Acute hydrocortisone myopathy in severe asthma. Thorax, 41:411-413, 1986.

30. Lacomis D, Giuliani MJ, Van Cott A, Kramer DJ. Acute myopathy of intensive care unit - clinical, electromyographic and pathological aspects. Ann Neurol, 40:645-658, 1996.

31. Hirano M, Ott BR, Raps EC. Acute quadriplegic myopathy a complication of steroids, nondespolarazing blocking agents or both. Neurology, 42:2082- 2089,1992.

32. Rich MM, Bird SJ, Raps EC. Direct muscle stimulation in acute quadriplegic myopathy. Muscle Nerve, 20:665-672, 1997.

33. Zochodne DW, Ramsay DA, Saly V. Acute necrotizing myopathy of intensive care - electrophysiological studies. Muscle Nerve, 17:285-293, 1994.

34. Faragher MW, Day BJ, Dennett X. Critical care myopathy an electrophysiological and histological study. Muscle Nerve, 19:516-522, 1996

35. Latronico N, Fenzi F, Recupero D. Critical illness myopathy and neuropathy. Lancet, 347:1570, 1996.

36. Zochodne DW, Ramsay DA, Robertson DM. A syndrome of acute severe muscle necrosis in intensive care unit patients. J Neurol Sci, 52:387-394, 1993.

37. Rich MM, Pinter MJ, Kraner SD, Barchi RL. Loss of electrical excitability in a animal model of in acute quadriplegic myopathy. Ann Neurol 43:171-178, 1998.

38. Rich MM, Teener JW, Rapps EC, Bird S. Muscle inexcitability with reversible paralysis following steroids and neuromuscular blockade. Muscle Nerve, 21:1231-1237, 1998.

39. Adams RJ, Rivner MH, Salazar J. Effects of oral calcium antagonists on neuromuscular transmission. Neurology, 34:132, 1984

40. Castlebaum AR, Donofrio PD, Walker FO. Laxative abuse causing hypermagnesemia, quadriparesis and neuromuscular junction defect. Neurology, 39:746-748, 1989.

41. Bashuk RG, Krendell DA. Myasthenia gravis presenting after magnesium administration. Muscle Nerve 13:708-713, 1990

42. Pittinger $\mathrm{C}$, Adamson R. Antibiotic blockade of neuromuscular function. Ann Rev Pharmacol, 12:164-184, 1972.

43. Swifft TR. Disorders of neuromuscular transmission other than myasthenia gravis. Muscle Nerve, 4:334-353, 1984.

44. Wilson RW, Ward MD, Johns TR. Corticosteroids - a direct effect on the neuromuscular transmission. Neurology, 24:1091-1095, 1974.

45. Miller RG, Millner-Brown HS. Prednisone-induced worsening of neuromuscular function in myasthenia gravis. Neurology, 36:729-732, 1986.

46. Atchison WD, Adgate L, Baerman CM. Effects of antibiotics on uptake of calcium into isolated nerve terminals. J Pharmacol Exp Ther, 245:394-401, 1988.

47. Rubbo JT, Girgis SD, Sokoll MD. Comparative neuromuscular effects of lincomycin and clindamycin. Anesth, 57:329-334, 1977

48. Lee DC, Kim Yi, Liu HM. Presynaptic and postsynaptic actions of procainamide on neuromuscular transmission. Muscle Nerve, 6:442-447, 1983.

49. Peterson $\mathrm{AH}$. Association of trimethadione therapy and myasthenia gravis. N Engl J Med, 274:506-507, 1966.

50. So EL, Penry JK. Adverse effects of phenytoin on peripheral nerves and neuromuscular junction - a review. Epilepsia, 22:467-473, 1989

51. Herishanu Y, Rosemberg P. Beta-blockers and myasthenia gravis. Na Intern Med. 83:834-836, 1973.

52. Granacher RP. Neuromuscular problems associated with lithium. Am J Psychiatry, 134:702, 1987.
53. Drosos AA, Christou L, Galanopolllou V, Tzioufas AG. dPenicillamine induced myasthenia gravis - clinical, serological and genetic findings. Clin Exp Rheumatol, 11:387391, 1993.

54. Kuncl RW, Pestronk A, Drachman DB, Recht-Roland E. The pathophysiology of penicillamine induced myasthenia gravis. Ann Neurol, 20:740-744, 1986.

55. Kauppinem R, Mustajoki. Prognosis of acute porphyria occurence of acute attacks, precipitating factors and associated diseases. Medicine, 71:1-13, 1992

56. Moore MR. International review of drugs in acute porphyrias. Int J Biochem, 12:1089-1097, 1982.

57. Disler PB, Bleckenhorst GH, Eales L, Moore MR. Guidelines for drug prescription in patients with acute porphiria. South Afr Med J, 61:656-661, 1982.

58. Suarez JI, Cohen ML, Larken J, Kunch RN, Hricik DE, Daroff RB. Acute intermitent porphyria a clinicopathologic correlation. Neurology, 48:1678-1683, 1997.

59. Lazarus A, Mann SC, Caroff SN. The neuroleptic malignant syndrome and related conditions. Clinical Genetics, 39:6567, 1991.

60. Caroff SN, Mann SC. Neuroleptic malignat syndrome. Med Clin North Am, 77:185-202, 1993.

61. Deuschl G, Oepen G, Hermle L. Neuroleptic malignant syndrome. Pharmacopsychiat 20:168-170, 1989.

62. Otani $\mathrm{K}$, Horiuchi $\mathrm{M}$, Kondo $\mathrm{T}$. Is the predisposition to neuroleptic malignant syndrome genetically transmitted? $\mathrm{Br}$ J Psychiatry, 158:850-853, 1991.

63. Rosebush P, Stewart T. A prospective analysis of 24 episodes of neuroleptic malignant syndrome. Am J Psychiatry, 146:717-725, 1989.

64. Shalev A, Munitz H. Neuroleptic malignant syndrome-agent and host interaction. Acta Psychiatr Scand, 73:337-347, 1986.

65. Caroff SN, Mann SC, Lazarus A. Neuroleptic malignant syndrome - diagnostic issues. Ann Psychatry, 20:130-147, 1991.

66. Otsu K, Nishida K, Kimura Y, Kusuya T, Hori M. The point mutation Arg 614-cys in the calcium release channel of skeletal sarcoplasmic reticulum is responsible for hypersensivity to caffein and halothane in malignant hyperthermia. J Biol Chem, 269:9413-9415, 1994.

67. Gillard EF, Otsu K, Fuji J. A substitution of cysteine to arginine in the ryanodine receptor is potencially causative of human malignant hyperthermia. Genomics, 11:751-754, 1991.

68. Mickelson JR, Ross JA, Reed BK, Louis CF. Enhanced calcium-induced calcium release by sarcoplasmic reticulum vesicles from malignant hyperthermia suscetible pig muscle. Biochem Biophys Acta, 862:318, 1986.

69. Gronert GA, Mott J, Lee J. Etiology of malignant hyperthermia. Br J Med, 60:253-257, 1988.

70. McLennan DH, Phillips MS. Malignant hyperthermia. Science, 256:789-797, 1993.

71. Vitta CM, Decker A, Jedlika AE, George AL, HeimanPetterson T. Masseter muscle rigity associated with glycine 1306 to alaline mutation in the Na channel alfa subunit gene. Anesthesiology, 82:1097-1103, 1995.

\section{Endereço para correspondência:}

Acary Souza Bulle Oliveira

Unifesp-EPM - Disciplina de Neurologia

Rua Botucatu, 740 - Vila Clementino

04023-900 - São Paulo, SP 